\title{
Gold nanoparticles as physiological markers of urine internalization into urothelial cells in vivo
}

\author{
This article was published in the following Dove Press journal: \\ International Journal of Nanomedicine \\ II October 2013 \\ Number of times this article has been viewed
}

\author{
Samo Hudoklin' \\ Daša Zupančič' \\ Darko Makovec ${ }^{2}$ \\ Mateja Erdani Kreft' \\ Rok Romih' \\ 'Institute of Cell Biology, Faculty \\ of Medicine, University of Ljubljana, \\ Ljubljana, Slovenia; ${ }^{2}$ Department \\ for Materials Synthesis, Jozef Stefan \\ Institute, Ljubljana, Slovenia
}

Background: Urothelial bladder is the reservoir of urine and the urothelium minimizes the exchange of urine constituents with this tissue. Our aim was to test $1.9 \mathrm{~nm}$ biocompatible gold nanoparticles as a novel marker of internalization into the urothelial cells under physiological conditions in vivo.

Methods: We compared normal and neoplastic mice urothelium. Neoplastic lesions were induced by $0.05 \%$ N-butyl-N-(4-hydroxybutyl)nitrosamine $(B B N)$ in drinking water for 10 weeks. Nanoparticles, intravenously injected into normal and BBN-treated mice, were filtered through the kidneys and became constituents of the urine within 90 minutes after injection.

Results: Gold nanoparticles were densely accumulated in the urine, while their internalization into urothelial cells depended on the cell differentiation stage. In the terminally differentiated superficial urothelial cells of normal animals, nanoparticles were occasionally found in the endosomes, but not in the fusiform vesicles. Regions of exfoliated cells were occasionally found in the normal urothelium. Superficial urothelial cells located next to exfoliated regions contained gold nanoparticles in the endosomes and in the cytosol beneath the apical plasma membrane. The urothelium of BBN-treated animals developed flat hyperplasia with moderate dysplasia. The superficial cells of BBN-treated animals were partially differentiated as demonstrated by the lack of fusiform vesicles. These cells contained the gold nanoparticles distributed in the endosomes and throughout their cytosol.

Conclusion: Gold nanoparticles are a valuable marker to study urine internalization into urothelial cells in vivo. Moreover, they can be used as a sensitive marker of differentiation and functionality of urothelial cells.

Keywords: urinary bladder, urothelial plaques, membrane internalization, gold nanoparticles, cancer models, electron microscopy

\section{Introduction}

Urine is composed of numerous harmful metabolites, which are stored for prolonged time in the urinary bladder. ${ }^{1}$ For that, the primary function of urinary bladder is to prevent internalization of metabolites from bladder lumen into the underlying tissues and blood. ${ }^{2}$ This blood-urine permeability barrier has to remain functional during the stretching-contraction of the urinary bladder. ${ }^{3,4}$ The permeability barrier is formed by the apical plasma membrane of superficial urothelial cells, tight junctions, and inhibited endocytosis. ${ }^{4}$

The apical plasma membrane of normal superficial urothelial cells is characterized by the formation of urothelial plaques, which are detergent-resistant membrane domains made of ordered transmembrane proteins known as uroplakins. ${ }^{5-11}$ Urothelial plaques
Correspondence: Samo Hudoklin Institute of Cell Biology, Faculty of Medicine, University of Ljubljana, Vrazov trg 2, 1000 Ljubljana, Slovenia Tel +386 I5437680 Fax +386 I543768 I Email samo.hudoklin@mf.uni-lj.si 
cover $70 \%-90 \%$ of the apical plasma membrane, where they contribute to the transcellular permeability barrier for ie, urea, water, ammonia or small non-electrolytes, ${ }^{2,12}$ but do not prevent $\mathrm{CO}_{2}$ transport through the urothelium. ${ }^{13}$ In the urothelium, where superficial cells do not reach their terminal differentiation, as is the case during urothelial carcinogenesis, ${ }^{14-17}$ the permeability barrier function is decreased. ${ }^{4,18}$

Urothelial plaques also cover cytoplasmic fusiform vesicles (FVs), which are implicated in the transport and incorporation of the urothelial plaques into the apical plasma membrane. ${ }^{3,4,19}$ Nevertheless, involvement of FVs in the endocytosis of urothelial plaques from the apical plasma membrane is controversially discussed. ${ }^{3,4,19}$ If FVs are involved in the endocytosis from the luminal side of the bladder, they would inevitably capture some urine despite their flattened shape. ${ }^{20,21}$ Therefore, demonstrating whether FVs are involved or not in the internalization of urine constituents would enhance our understanding of the permeability barrier function of the urothelium.

A physiological approach to study the internalization of urine would be the introduction of nanoparticles as urine constituents. Nanoparticles are small enough to be filtered through the kidneys and are accumulated in the bladder lumen, they are biologically inert, and they do not influence endocytotic processes. . $^{22,23}$

In this study, we tested $1.9 \mathrm{~nm}$ ultra-small gold nanoparticles (AuNPs), covered by a highly water soluble organic shell, as markers for studying endocytosis in normal and neoplastic urothelium under in vivo conditions. Using light and electron microscopy, we show that intravenously injected AuNPs reach the urinary bladder and act as physiological constituents of urine. Moreover, internalization of AuNPs into urothelial cells is dependent on their differentiation stage.

\section{Material and methods Animals and treatment}

Experiments were approved by the Veterinary Administration of the Slovenian Ministry of Agriculture and Forestry (permit no 34401-29/2007/3) in compliance with the Animal Health Protection Act and the Instructions for Granting Permits for Animal Experimentation for Scientific Purposes. Adult male mice, strain $\mathrm{A} / \mathrm{J}$ Ola Hsd, were housed in plastic cages at $23^{\circ} \mathrm{C} \pm 2{ }^{\circ} \mathrm{C}$, at $50 \%-60 \%$ relative humidity and at 12 -hour light/dark circadian cycle.

Ten animals were divided into three groups by simple random sampling: two animals were fed normal diet and were not injected with AuNPs, but were injected with a $0.9 \% \mathrm{NaCl}$ physiological solution (control animals), four animals were fed normal diet and were then injected with AuNPs (AuNPs-N animals), and four animals were N-butylN-(4-hydroxybutyl)nitrosamine (BBN) treated and were then injected with AuNPs (AuNPs-BBN animals).

BBN (Tokyo Chemical Industry Co, Ltd, Tokyo, Japan) was diluted to $0.05 \%$ with tap water and this mixture was provided as drinking water (ad libitum) to AuNPs-BBN animals for 10 weeks. Control and AuNPs-N animals had tap water available ad libitum. Basal diet was available ad libitum.

On the day of experiment, animals were anesthetized with 2\% Chanazine (Chanelle Pharmaceuticals Manufacturing Ltd, Loughrea, Ireland; $5 \mu \mathrm{L} / 100 \mathrm{~g}$ body weight) and 10\% Bioketan (Vetoquinol Biowet, Gorzów, Poland; $10 \mu \mathrm{L} / 100 \mathrm{~g}$ body weight). Once sedated, AuNPs-N and AuNPs-BBN animals were injected with $200 \mu \mathrm{L}$ of the AuNPs solution into the tail vein. The AuNPs solution was prepared as follows: forty milligrams of $1.9 \mathrm{~nm}$ AuroVist gold nanoparticles (Nanoprobes, Yaphank, NY, USA) were diluted in $400 \mu \mathrm{L}$ of physiologic solution according to manufacturer recommended protocol to obtain the final concentration of approximately $1.4 \mathrm{~g} \mathrm{Au} / \mathrm{kg}$ body mass. The color of AuNPs solution was black. The animals from the control group were injected with $200 \mu \mathrm{L}$ of physiologic solution into the tail vein. All animals were killed with $\mathrm{CO}_{2}$ inhalation 90 minutes after injection. The urinary bladders were exposed with abdominal incision and fixed with $4 \%$ paraformaldehyde in phosphate saline buffer without potassium (PBS-K ${ }^{+}$) for 3 minutes, applied from the serosa side in situ. Next bladders were removed from the animals and dissected into multiple pieces in the same fixative. Samples from each of the bladders were further processed for light, transmission (TEM), and scanning (SEM) electron microscopy.

\section{Urine}

Urine was collected; a $5 \mu \mathrm{L}$ drop of urine was put on gold electron microscopy grids, dried, and either directly observed or processed for AuNPs intensification. HQ silver enhancement (nanoprobes) and gold enhanced (nanoprobes) were used to enlarge gold nanoparticles. Both silver and gold enhanced solutions were prepared and used according to manufacturer recommended protocols with enhancement times of 4 and 5 minutes, respectively. Grids were observed under TEM CM100 (Philips, Amsterdam, the Netherlands).

\section{Histology}

The urinary bladder samples were fixed in 4\% paraformaldehyde in $\mathrm{PBS}\left(-\mathrm{K}^{+}\right)$at $4^{\circ} \mathrm{C}$ overnight, dehydrated, and embedded 
in paraffin. Paraffin blocks were cut into serial sections and counterstained with hematoxylin and eosin and examined by a uropathologist. Histological urothelial changes of AuNPs-BBN animals were classified according to World Health Organization (WHO) classification of tumors of the urinary tract. ${ }^{24}$

\section{Ultrastructure and internalization of AuNPs}

The urinary bladder samples were fixed in $4 \%$ paraformaldehyde in PBS $\left(-\mathrm{K}^{+}\right)$at room temperature for a total of 45 minutes. After fixation, the samples were washed in PBS $\left(-\mathrm{K}^{+}\right)$, then in deionized water, and finally in the citrate buffer. The samples were then incubated in the HQ silver enhancement solution (nanoprobes) and prepared according to manufacturer protocol in the dark for 5.5 minutes. After washing in deionized water, the samples were post-fixed in $0.2 \% \mathrm{OsO}_{4}$ for 75 minutes, washed in $0.1 \mathrm{M}$ cacodylate buffer, dehydrated in graded ethanol, and embedded in Epon. Semi-thin sections (thickness $1 \mu \mathrm{m}$ ), were stained with $1 \%$ toluidine and examined with an Eclipse TE300 inverted microscope (Nikon, Tokyo, Japan). From the regions of interest, the ultrathin sections $(50 \mathrm{~nm})$ were cut and counterstained with lead citrate and uranyl acetate. Next, they were examined with a CM100 TEM (Philips) running at $80 \mathrm{kV}$.

The urinary bladder samples from AuNPs-BBN animals were also prepared using the modified Tokuyasu method. ${ }^{25}$ Briefly, urothelium, cut into $<1 \mathrm{~mm}^{3}$ pieces, was fixed in $4 \%$ paraformaldehyde in PBS $\left(-\mathrm{K}^{+}\right)$at room temperature for 2 hours, washed in $\mathrm{PBS}\left(-\mathrm{K}^{+}\right)$, embedded into $12 \%$ gelatine, and cryoprotected by incubation in $2.3 \mathrm{M}$ saharose at $4^{\circ} \mathrm{C}$ overnight. Samples were then stored in liquid nitrogen. Subsequently, $300 \mathrm{~nm}$ thick cryosections were cut with FCS cryo-ultramicrotome (Leica Microsystems, Wetzlar, Germany) at $-100^{\circ} \mathrm{C}$ and collected on glass cover slips. Nanoparticles in cryo-sections were silver enhanced with the HQ silver enhancement solution (nanoprobes) in the dark for 6 minutes, washed in deionized water, and counterstained with toluidine and examined with an Eclipse TE300 inverted microscope (Nikon). From the regions of interest the cryo-ultrathin sections $(50 \mathrm{~nm})$ were cut and counterstained with uranil acetate-methyl cellulose mixture.

Energy dispersive X-ray spectroscopy (EDXS) analysis was performed using a transmission electron microscope 2100 (Jeol, Tokyo, Japan) equipped with an EDX system EX-23003BU (Jeol). The TEM was operated at $200 \mathrm{kV}$.

\section{Apical surface}

The urinary bladder samples were fixed in $4 \%$ paraformaldehyde plus $2 \%$ glutaraldehyde in $0.1 \mathrm{M}$ cacodylate buffer at $4^{\circ} \mathrm{C}$ for 3 hours, washed overnight in cacodylate buffer, dehydrated in a series of ethanol, and critical-point dried (CPD030 Baltec, Balzers, Liechtenstein). After sputter-coating with gold (Balzers Union SCD040, Balzers, Liechtenstein), samples were examined with a JSM840A scanning electron microscope (Jeol) at $15 \mathrm{kV}$.

\section{Cell viability}

The cultures of normal porcine urothelial cells ( 5 th passage) were established on 12-well culture inserts with $0.4 \mu \mathrm{m}$ porous membranes (BD Falcon, San Jose, CA, USA) and maintained in UroM media as described previously. ${ }^{26,27}$ When cultures reached confluence, they were divided into two groups by simple random sampling: treated cells and control cells. AuroVist AuNPs (nanoprobes), in the same concentration as were injected into experimental animals, were added to the UroM media of treated cells. Control cells were kept in the UroM media without AuNPs. After 90 minutes, cells were detached by using TripLE Select (Gibco, Life Technologies, Carlsbad, CA, USA), centrifuged, and resuspended in fresh UroM media. Viability of cells was then determined by Trypan Blue (Gibco) staining. The survival of cells treated with AuNPs is presented as the percentage of the Trypan Blue-labeled cells versus non-labeled cells; average, standard deviation (SD), and Student's $t$-test were performed with Excel 2010 software (Microsoft Corporation, Redmond, WA, USA).

\section{Results Gold nanoparticles become urine constituents and accumulate in the urinary bladder}

All animals survived the injection of AuNPs or physiologic solution into the tail vein and fully recovered after anesthesia. AuNPs were filtered through the kidneys and reached the urinary bladder after 90 minutes, which was evaluated both macro- and microscopically (Figure 1). Macroscopically, lumen of the urinary bladders turned black in the AuNPs-N (Figure 1A and B) and AuNPs-BBN animals, while in the control animals they remained translucent. The presence of AuNPs was confirmed in the urine (Figure 1C) by TEM (Figure 1D). The concentration of AuNPs in the urine was high (Figure 1D), so that it was not a limiting factor for detection. To make AuNPs easily detected by TEM, we tested if they were suitable for silver or gold enhancement. The results showed that the gold core of nanoparticles can be enlarged by both methods (Figure 1E and F). Gold enhancement provided a more uniform size of enlarged nanoparticles than silver 

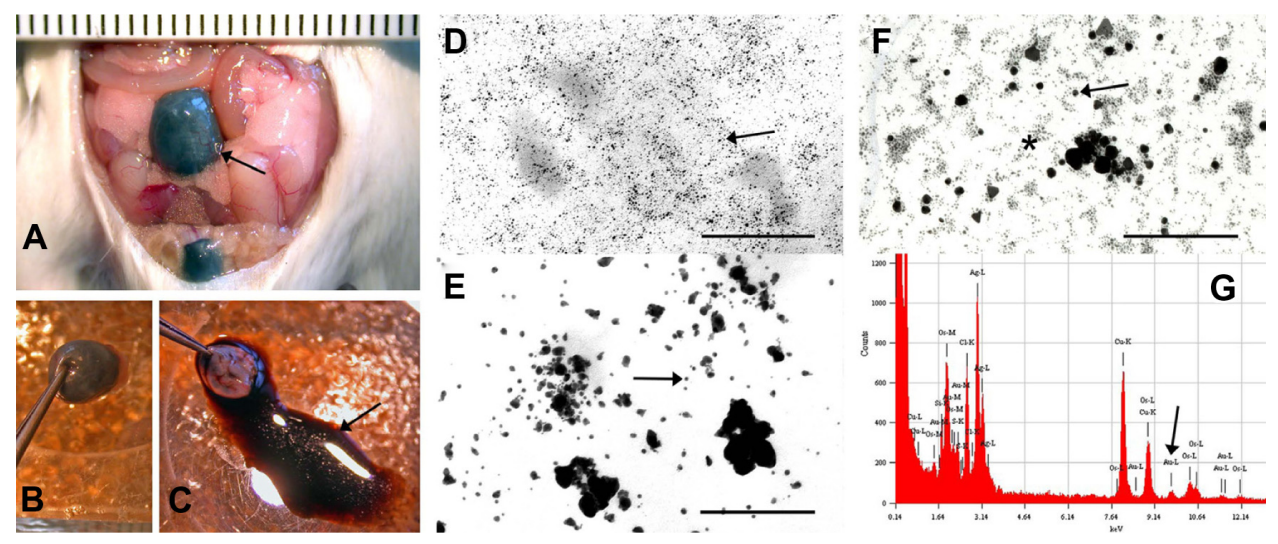

Figure I Gold nanoparticles reach the urinary bladder of AuNPs-N animals and can be visualized macroscopically (A-C) and microscopically under TEM (D-F). Notes: (A) Ninety minutes after intravenous injection of nanoparticles, the urinary bladder (arrow) was colored black. (B) Excised urinary bladder from (A). (C) The black colored fluid (arrow) from the excised urinary bladder (B). (D) A drop of fluid from (C) analyzed under TEM; individual nanoparticles are seen (arrow). (E) AuNPs after silver enhancement. Enlarged nanoparticles are easy to see (arrow). (F) AuNPs after gold enhancement. Enlarged (arrow) and non-enlarged (asterisk) nanoparticles are seen. (G) EDXS analysis made of the particles-containing endosomes of the superficial urothelial cell. Diagram shows a peak of elementary gold (arrow). Bar length is in millimeter scale in (A), and $100 \mathrm{~nm}$ in (D-F).

Abbreviations: AuNPs, ultra-small gold nanoparticles; AuNPs-N animals, animals that were fed with normal diet and were then injected with AuNPs; EDXS, energy dispersive X-ray spectroscopy; TEM, transmission electron microscope.

enhancement, but on the other hand, many particles remained unenhanced. Therefore, silver enhancement was used in further experiments. Under light microscopy (LM), the reaction product of silver enhancement was brown. To prove that the silver enhancement reaction specifically enlarges AuNPs in the tissue, ultrathin-sections of the urothelium were analyzed by EDXS. Results have confirmed that nanoparticles seen as accumulation of electron-dense material in TEM contained elementary gold (Figure 1G). Analysis of a large number of the individual nanoparticles always showed co-localization of $\mathrm{Ag}$ (silver) and $\mathrm{Au}$, whereas in areas of the samples without the nanoparticles, Au could not be detected.

\section{Gold nanoparticles are not toxic for urothelial cells}

To verify the low toxicity of AuNPs, they were added to the medium of urothelial cell culture at the same concentration as the AuNPs-N and AuNPs-BBN in experimental animals. After 90 minutes, the viability of control cells was $90.3 \% \pm 12 \%$, while the treated cells had a viability of $78.2 \% \pm 5 \%$; the difference was statistically significant, $P<0.001$.

\section{Internalization of gold nanoparticles is minimal in terminally differentiated urothelial cells}

To test if AuNPs are internalized by the superficial urothelial cells, we analyzed urinary bladder samples under light and electron microscopes. Under LM, the urothelia of control and AuNPs-N animals consisted of three cell layers: small basal, intermediate, and large superficial cells (Figure 2A). Brown-labeled product of silver enhancement was not seen in any layer of the urothelial or in the blood vessels of the urinary bladder wall (Figure 2A). Under electron microscopes, the superficial urothelial cells of control and AuNPs-N animals were observed as large, homogenous, and polygonal shaped (Figure 2B), and contained numerous FVs in their cytoplasm (Figure 2C). In the AuNPs-N animals, AuNPs were not detected in approximately three out of four superficial cells (Figure 2C). In one fourth of the superficial urothelial cells, AuNPs were observed in membrane compartments with $300-1200 \mathrm{~nm}$ diameter, which were presumably endosomes (Figure 2D and E). FVs and other cellular compartments did not contain nanoparticles. Epithelial intracellular spaces, lamina propria, blood vessels, and bladder muscles were also unlabeled (Figure 2F).

\section{Gold nanoparticles penetrate urothelial cells bordering exfoliated regions}

Occasionally, the regions of exfoliated urothelium were observed in semi-thin sections of the normal urothelium of control and AuNPs-N animals. These regions were limited to one or a few superficial cells (Figure 3A). In the AuNPs-N animals, regions of exfoliated urothelium were surrounded by apically labeled cells (Figure 3A and B). Labeling was seen only in the superficial cell layer and was present in an all-or-nothing manner; eg, by observing 


\section{A}
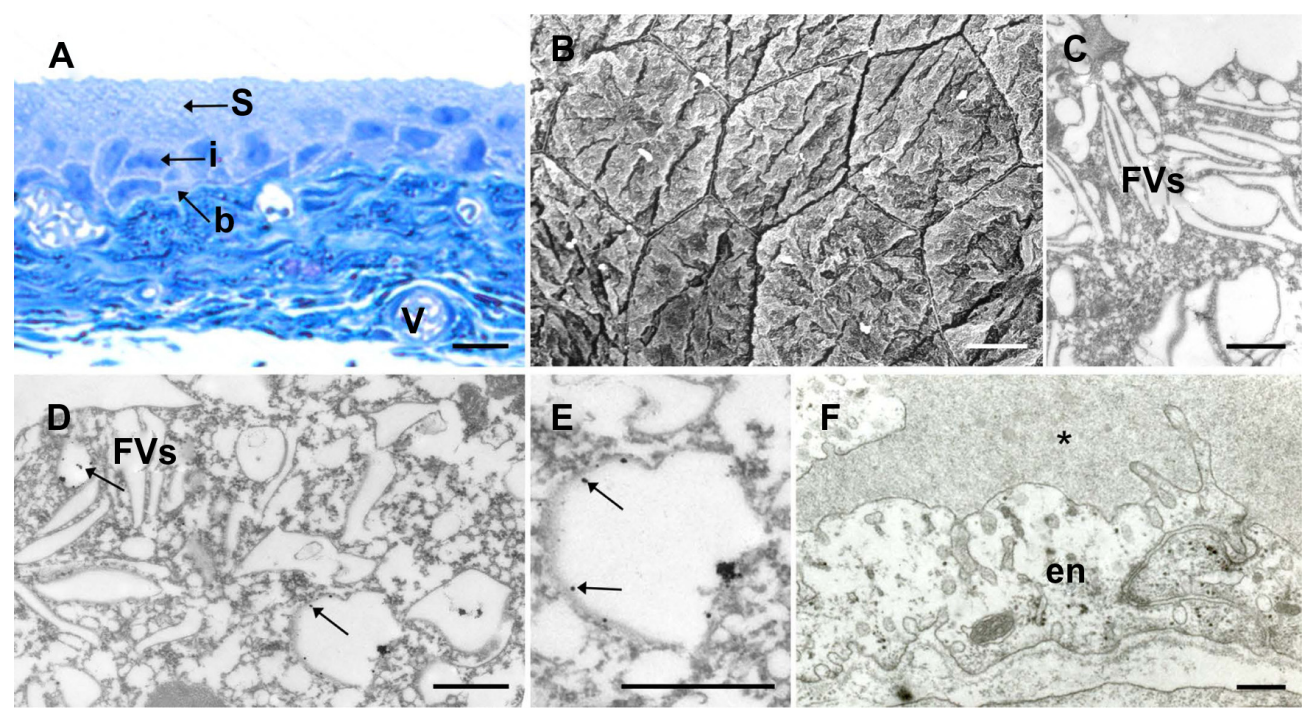

Figure 2 Internalization of gold nanoparticles into terminally differentiated superficial urothelial cells of the AuNPs-N animals.

Notes: (A) LM; no brown labeling is seen in the urothelium or in the blood vessels of the bladder wall. (B) SEM; differentiated superficial urothelial cells are large homogenous, polygonal cells. (C) TEM; superficial cells contain fusiform vesicles, but no gold nanoparticles. (D) TEM; superficial cell contains membrane compartments with gold nanoparticles (arrows; magnification in [E]). (F) TEM; in the urinary bladder endothelial cells, no nanoparticles are observed; asterisk*: vein lumen. Bar length is $10 \mu \mathrm{m}$ $(\mathbf{A}$ and $\mathbf{B}), 500 \mathrm{~nm}$ in (C), and $250 \mathrm{~nm}$ in (D-F). Arrows show position of cells.

Abbreviations: b, basal cells; en, endothelial cells; FVs, fusiform vesicles; i, intermediate; LM, light microscopy; S, superficial; SEM, scanning electron microscopy; TEM, transmission electron microscopy; $\mathrm{V}$, blood vessels; AuNPs-N animals, animals that were fed with normal diet and were then injected with AuNPs; AuNPs, ultra-small gold nanoparticles.

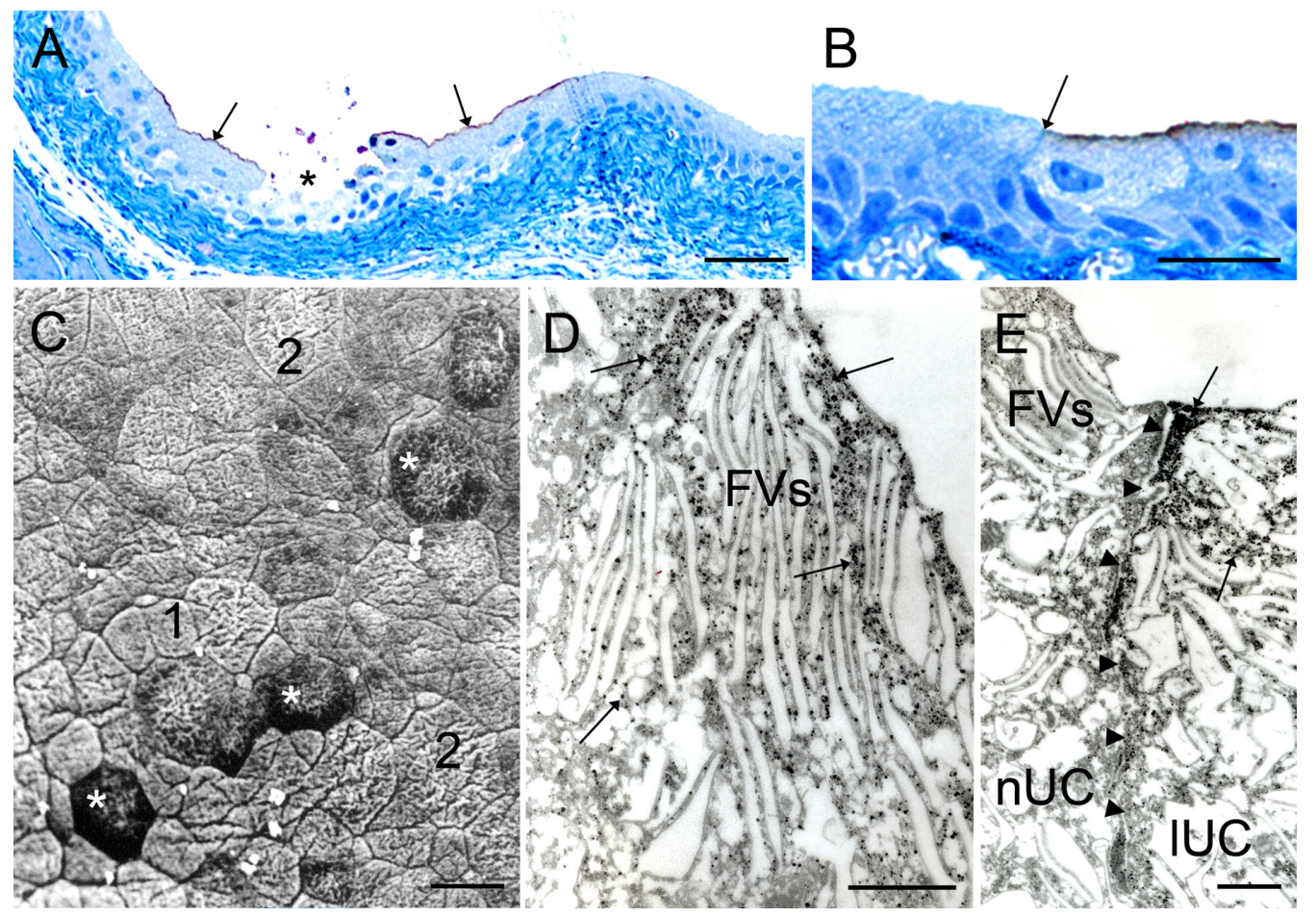

Figure 3 Internalization of gold nanoparticles into superficial urothelial cells bordering the regions of exfoliated urothelial cells of the AuNPs- $\mathrm{N}$ animals.

Notes: (A) LM; superficial cells bordering regions of exfoliated cells (asterisk) are labeled (arrows). (B) LM; labeling is seen as a line in the superficial region of cells and ends sharply at the border with the non-labeled cells (arrow). (C) SEM; Region of normal urothelium where exfoliation of superficial cells took place; cells that replace exfoliated cells (asterisk) are surrounded by relatively small cells (presumably regenerating cells, [I]); and further away are large, polygonal cells (presumably old differentiated cells, [2]). (D) TEM; nanoparticles (arrows) in the cytosol, but not in the fusiform vesicles of labeled superficial cells. (E) TEM; neighboring superficial urothelial cells with fusiform vesicles; the non-labeled cell ( $\mathrm{nUC}$ ) on the left does not contain nanoparticles, while the labeled cell (IUC) on the right is permeable and contains nanoparticles in the cytosol (arrows). Arrowheads delineate lateral border between the cells. Bar length is $50 \mu \mathrm{m}$ in (A), $25 \mu \mathrm{m}$ in (B and C), and $500 \mathrm{~nm}$ in (D and E).

Abbreviations: AuNPs-N animals, animals that were fed with normal diet and were then injected with AuNPs; AuNPs, ultra-small gold nanoparticles; FVs, fusiform vesicles; IUC, labeled urothelial cells; nUC, non-labeled urothelial cells; LM, light microscopy; SEM, scanning electron microscopy; TEM, transmission electron microscopy. 
two cells, one contained a relatively constant amount of brown labeling while the neighboring superficial cell contained no labeling at all (Figure 3B). SEM analysis of the apical urothelial surface revealed cells of different sizes; relatively small cells next to exfoliated regions and large polygonal cells further away from these areas (Figure 3C). Under TEM, labeled cells showed FVs, which are characteristic of highly differentiated urothelial cells (Figure 3D and E). These cells were heavily loaded with AuNPs with the majority of them found in the cytosol (Figure 3D and E). The highest concentration of AuNPs was underneath the apical plasma membrane. Membrane compartments, presumably endosomes, also contained AuNPs, but not FVs. AuNPs were detected also in the intracellular spaces between labeled cells. The sharp boundary between labeled and non-labeled cells was seen (Figure 3E).

\section{Internalization of gold nanoparticles is increased during urothelial carcinogenesis}

In order to follow the internalization of AuNPs into the neoplastic urothelium, we induced urothelial carcinogenesis with $0.05 \% \mathrm{BBN}$ in drinking water. After 10 weeks of BBN administration, the urothelium of AuNPs-BBN animals developed flat hyperplasia with moderate dysplasia. In these regions, the brown labeling was observed in the majority of superficial cells, in the significant portion of intermediate cells, and in some basal cells (Figure 4A). Relatively small superficial cells of dysplastic urothelium were covered with microvilli and ropy ridges (Figure 4B) and their apical cytoplasm contained no FVs (Figure 4C). These are characteristics of partially differentiated urothelial cells. The labeling was seen in the vesicular compartments, presumably endosomes, as well as in the cytosol (Figure 4D).

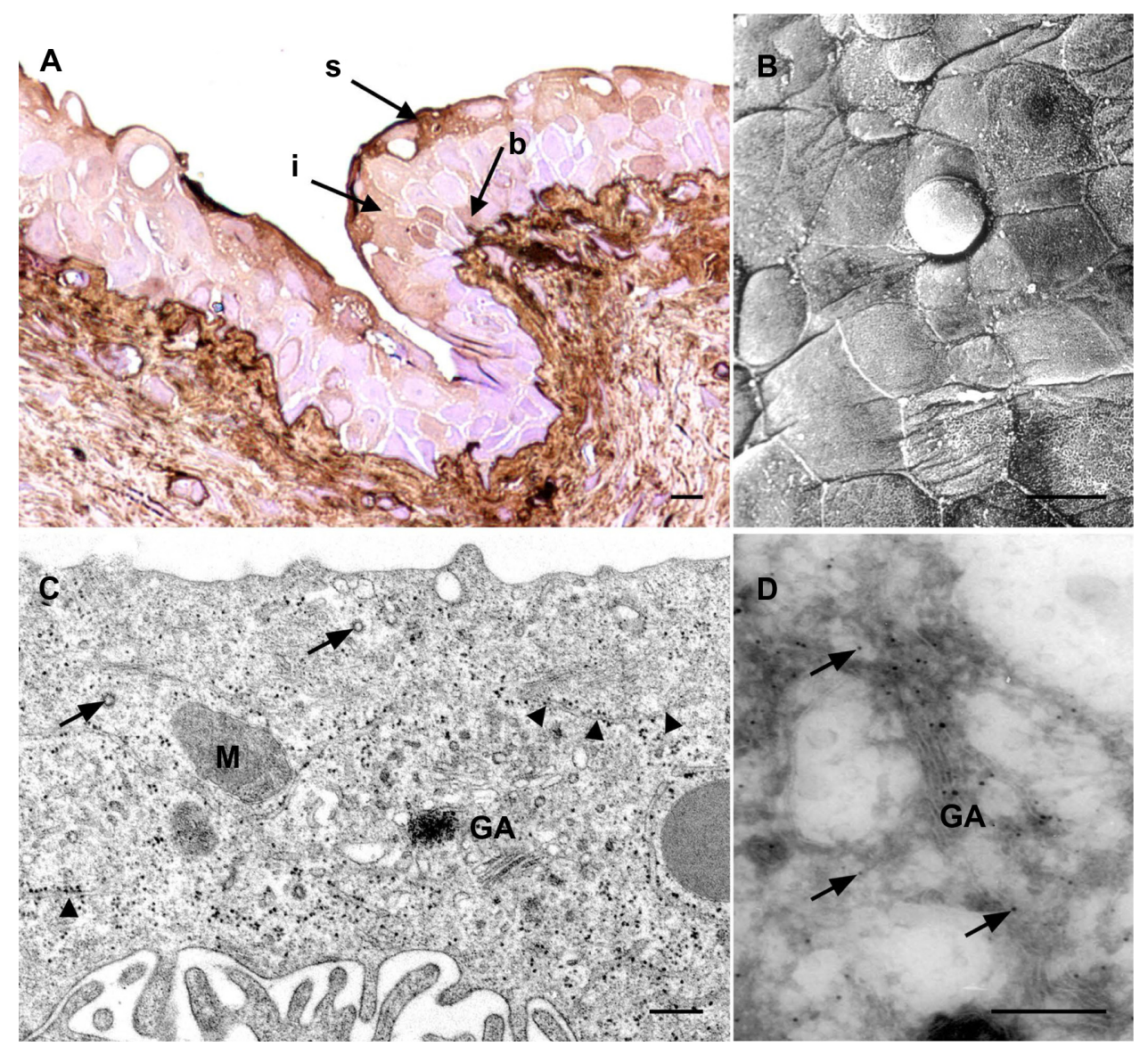

Figure 4 Internalization of gold nanoparticles into urothelial cells of AuNPs-BBN animals.

Notes: (A) LM; brown-labeled (arrows) superficial, intermediate, and basal urothelial cells are seen in the dysplastic urothelium. (B) SEM; Superficial urothelial cells are heterogeneous and small. (C) TEM; granular endoplasmic reticulum (arrowheads), GA, M, and coated-vesicles (arrows) are found in the superficial urothelial cell, however no FVs. (D) TEM; nanoparticles (arrows) in the superficial urothelial cell. Bar length is $10 \mu \mathrm{m}$ in (A and B), and $250 \mathrm{~nm}$ in (C and D).

Abbreviations: AuNPs-BBN animals, animals that were N-butyl- N-(4-hydroxybutyl)nitrosamine (BBN) treated and were then injected with AuNPs; AuNPs, ultra-small gold nanoparticles; N-butyl-N-(4-hydroxybutyl)nitrosamine diet; b, basal; GA, Golgi apparatus; i, intermediate; LM, light microscopy; M, mitochondria; FV, fusiform vesicles; s, superficial; SEM, scanning electron microscopy; TEM, transmission electron microscopy. 


\section{Discussion}

Great care should be devoted to the choice of endocytotic markers and the method of their application in order to study endocytosis in vivo under physiological conditions. We have selected AuNPs that fulfill three requests: (1) biocompatibility, (2) size, and (3) ability to detect.

1. Biocompatibility of the material. AuNPs have a relatively long history in biological applications and have been confirmed biocompatible by various in vitro and in vivo experiments. ${ }^{23,28-32}$ In our study, the viability of cultured cells exposed to the highest recommended concentration of AuNPs was lower than of control cultured cells ( $78.2 \% \pm 5 \%$ versus $90.3 \% \pm 12 \%$ ); however, the survival rate was still acceptable and well above $\mathrm{LD}_{50}$ (median lethal dose). Moreover, all animals survived the tail vein injection of AuNPs and fully recovered after 90 minutes of anesthesia. Therefore, we consider the use of AuNPs safe.

2. Size of nanoparticles. Based on the standard definition of the American Society for Testing and Materials, nanoparticles are particles with lengths that range from 1 to $100 \mathrm{~nm}$ in two or three dimensions. The AuNPs we used, with their gold core $1.9 \mathrm{~nm}$ in diameter, are on the smaller side of the nanoparticle definition scale that is a prerequisite for substances to pass the macromolecular filter in the kidney. In our study, intravenously injected AuNPs were detected in the urine, which suggests that AuNPs are filtered in the kidneys and become constituents of the urine under physiological conditions.

3. Ability to detect nanoparticles. Colloidal gold with diameters above $5 \mathrm{~nm}$ have sufficient electron density to be visualized in ultrathin sections of biological samples by TEM. AuNPs used in our study can be seen under TEM when directly applied to a TEM grid, but are too small to be easily recognized in the ultrathin sections of the tissues. However, after silver or gold enhancement, ${ }^{33-36}$ nanoparticles are clearly seen. We confirmed specificity of the enhancement reaction by TEM and EDXS analysis and showed that silver enhancement enlarges a higher percentage of nanoparticles than gold enhancement. With the three basic requests fulfilled, the AuNPs can be used as a potential marker to follow internalization into urothelial cells from the luminal side of the urinary bladder under physiological conditions in vivo.

Since there are contradicting results regarding endocytosis in urothelial cells, ${ }^{3,19,37,38}$ we used the AuNPs to follow internalization into superficial urothelial cells of normal and neoplastic urothelium.
In the terminally differentiated superficial urothelial cells of normal urothelium, internalization of the AuNPs was minimal, which is in agreement with our previous study on urothelial cells in vitro. ${ }^{38}$ Despite the high concentration of nanoparticles in the bladder lumen, only one quarter of cells contained a few labeled endosomes, which shows extremely low dynamics of endocytosis compared to other cell types. ${ }^{38}$ Nanoparticles were not found in the $\mathrm{FVs}$, demonstrating that FVs are not involved in the removal of urothelial plaques from the apical plasma membrane. Limited internalization of nanoparticles into terminally differentiated superficial urothelial cells hence supports the idea that internalization of urine and its constituents is minimized, which contributes to the barrier function of the urothelium. ${ }^{4}$

In the normal urothelium, terminally differentiated superficial cells have an extremely long life time; ${ }^{39,40}$ however, they are occasionally removed by exfoliation and the exfoliated areas are rapidly resealed. ${ }^{41-44}$ In our study, we observed regions of exfoliated urothelium in control and in AuNPs-N animals, and in either case exfoliated regions were surrounded by differentiated, but smaller urothelial cells. In AuNPs-N animals, these cells contained nanoparticles indicating that what is observed are regenerating cells, which have not yet established a fully functional permeability barrier.

To further explore the functionality of the permeability barrier during alternative differentiation, we applied AuNPs to AuNPs-BBN animals. BBN is widely used in the urothelial carcinogenesis model systems and prevents urothelial cells reaching their terminal differentiation. ${ }^{45,46} \mathrm{~A}$ consequence of low cellular differentiation is leaky epithelium, ${ }^{38,47}$ which was also observed in our study. The AuNPs were commonly found in the partially differentiated cells of neoplastically transformed urothelium. The increased internalization into superficial cells of dysplastic urothelium in comparison to normal superficial cells reveals the potential that nanoparticles could be used in improved diagnostic and optimized treatment of urinary bladder cancer. ${ }^{31,48-51}$ However, the increased nanoparticle internalization is not an explicit property of the partially differentiated cells found in the neoplastically transformed urothelium, but is also seen in normal urothelial cells located next to the exfoliated regions of the urothelium. Therefore, the AuNPs above can all be used to follow endocytosis as well as be used as a sensitive marker of differentiation and functionality in urothelial cells. 


\section{Conclusion}

Our experiments were intended to determine the physiological conditions for studying internalization in superficial urothelial cells in vivo. We provide evidence that the AuNPs we used are an excellent choice for the given studies, both on normal and in neoplastic urinary bladders. Our results support the hypothesis that endocytosis is very limited in terminally differentiated urothelial cells, while the internalization of urine constituents increases significantly when the urothelial cells are at a lower differentiation stage. The conception of the latter provides solid ground for the developing novel, more effective bladder cancer diagnostic and treatment tools using nanoparticles.

\section{Acknolwedgment}

This study was supported by a grant from the Slovenian Research Agency ARRS [P3-0108].

\section{Disclosure}

The authors report no conflicts of interest in this work.

\section{References}

1. Johansson SL, Cohen SM. Epidemiology and etiology of bladder cancer. Semin Surg Oncol. 1997;13(5):291-298.

2. Hicks RM. The mammalian urinary bladder: an accommodating organ. Biol Rev Camb Philos Soc. 1975;50(2):215-246.

3. Apodaca G. The uroepithelium: not just a passive barrier. Traffic. 2004;5(3):117-128.

4. Kreft ME, Hudoklin S, Jezernik K, Romih R. Formation and maintenance of blood-urine barrier in urothelium. Protoplasma. 2010;246(1-4):3-14.

5. Hicks RM. The fine structure of the transitional epithelium of rat ureter. $J$ Cell Biol. 1965;26(1):25-48.

6. Kachar B, Liang F, Lins U, et al. Three-dimensional analysis of the $16 \mathrm{~nm}$ urothelial plaque particle: luminal surface exposure, preferential head-to-head interaction, and hinge formation. J Mol Biol. 1999;285(2): 595-608.

7. Min G, Wang H, Sun TT, Kong XP. Structural basis for tetraspanin functions as revealed by the cryo-EM structure of uroplakin complexes at 6-A resolution. J Cell Biol. 2006;173(6):975-983.

8. Porter KR, Kenyon K, Badenhausen S. Specializations of the unit membrane. Protoplasma. 1967;63(1):262-274.

9. Veranic P, Romih R, Jezernik K. What determines differentiation of urothelial umbrella cells? Eur J Cell Biol. 2004;83(1):27-34.

10. Wu XR, Manabe M, Yu J, Sun TT. Large scale purification and immunolocalization of bovine uroplakins I, II, and III. Molecular markers of urothelial differentiation. J Biol Chem. 1990;265(31):19170-19179.

11. Yu J, Manabe M, Wu XR, Xu C, Surya B, Sun TT. Uroplakin I: a 27-kD protein associated with the asymmetric unit membrane of mammalian urothelium. J Cell Biol. 1990;111(3):1207-1216.

12. Negrete HO, Lavelle JP, Berg J, Lewis SA, Zeidel ML. Permeability properties of the intact mammalian bladder epithelium. Am J Physiol. 1996;271(4 Pt 2):F886-F894.

13. Zocher F, Zeidel ML, Missner A, et al. Uroplakins do not restrict CO2 transport through urothelium. J Biol Chem. 2012;287(14): 11011-11017.
14. Wu RL, Osman I, Wu XR, et al. Uroplakin II gene is expressed in transitional cell carcinoma but not in bilharzial bladder squamous cell carcinoma: alternative pathways of bladder epithelial differentiation and tumor formation. Cancer Res. 1998;58(6):1291-1297.

15. Wu XR. Urothelial tumorigenesis: a tale of divergent pathways. Nat Rev Cancer. 2005;5(9):713-725.

16. Zupančič D, Ovčak Z, Vidmar G, Romih R. Altered expression of UPIa, UPIb, UPII, and UPIIIa during urothelial carcinogenesis induced by N-butyl-N-(4-hydroxybutyl)nitrosamine in rats. Virchows Arch. 2011;458(5):603-613.

17. Zupančič D, Zakrajšek M, Zhou G, Romih R. Expression and localization of four uroplakins in urothelial preneoplastic lesions. Histochem Cell Biol. 2011;136(4):491-500.

18. Kreft ME, Jezernik K, Kreft M, Romih R. Apical plasma membrane traffic in superficial cells of bladder urothelium. Ann N Y Acad Sci. 2009;1152:18-29.

19. Wu XR, Kong XP, Pellicer A, Kreibich G, Sun TT. Uroplakins in urothelial biology, function, and disease. Kidney Int. 2009;75(11):1153-1165.

20. Derganc J, Božič B, Romih R. Shapes of discoid intracellular compartments with small relative volumes. PLoS ONE. 2011;6(11): e26824.

21. Hudoklin S, Jezernik K, Neumüller J, Pavelka M, Romih R. Electron tomography of fusiform vesicles and their organization in urothelial cells. PLoS ONE. 2012;7(3):e32935.

22. Erathodiyil N, Ying JY. Functionalization of inorganic nanoparticles for bioimaging applications. Acc Chem Res. 2011;44(10):925-935.

23. Bhattacharya R, Mukherjee P. Biological properties of "naked" metal nanoparticles. Adv Drug Deliv Rev. 2008;60(11):1289-1306.

24. Eble JN, Sauter G, Epstein JI, Sesterhenn IA. World Health Organization Classification of Tumors. Pathology and genetic of tumors of the urinary system and male genital organs. Lyon, France: IARC Press; 2004.

25. Tokuyasu KT. A technique for ultracryotomy of cell suspensions and tissues. J Cell Biol. 1973;57(2):551-565.

26. Kreft ME, Hudoklin S, Sterle M. Establishment and characterization of primary and subsequent subcultures of normal mouse urothelial cells. Folia Biol (Praha). 2005;51(5):126-132.

27. Višnjar T, Kocbek P, Kreft ME. Hyperplasia as a mechanism for rapid resealing urothelial injuries and maintaining high transepithelial resistance. Histochem Cell Biol. 2012;137(2):177-186.

28. Bakri SJ, Pulido JS, Mukherjee P, Marler RJ, Mukhopadhyay D. Absence of histologic retinal toxicity of intravitreal nanogold in a rabbit model. Retina (Philadelphia, Pa). 2008;28(1):147-149.

29. Connor EE, Mwamuka J, Gole A, Murphy CJ, Wyatt MD. Gold nanoparticles are taken up by human cells but do not cause acute cytotoxicity. Small. 2005;1(3):325-327.

30. Goodman CM, McCusker CD, Yilmaz T, Rotello VM. Toxicity of gold nanoparticles functionalized with cationic and anionic side chains. Bioconjug Chem. 2004;15(4):897-900.

31. Hainfeld JF, Slatkin DN, Focella TM, Smilowitz HM. Gold nanoparticles: a new X-ray contrast agent. Br J Radiol. 2006;79(939):248-253.

32. Mukherjee $P$, Bhattacharya $\mathrm{R}$, Bone N, et al. Potential therapeutic application of gold nanoparticles in B-chronic lymphocytic leukemia (BCLL): enhancing apoptosis. J Nanobiotechnology. 2007;5:4.

33. Humbel BM, Sibon OC, Stierhof YD, Schwarz H. Ultra-small gold particles and silver enhancement as a detection system in immunolabeling and in situ hybridization experiments. $J$ Histochem Cytochem. 1995;43(7):735-737.

34. Burry RW, Vandré DD, Hayes DM. Silver enhancement of gold antibody probes in pre-embedding electron microscopic immunocytochemistry. J Histochem Cytochem. 1992;40(12):1849-1856.

35. Baschong W, Stierhof YD. Preparation, use, and enlargement of ultrasmall gold particles in immunoelectron microscopy. Microsc Res Tech. 1998;42(1):66-79.

36. Hainfeld JF, Powell RD. New frontiers in gold labeling. J Histochem Cytochem. 2000;48(4):471-480. 
37. Yu W, Khandelwal P, Apodaca G. Distinct apical and basolateral membrane requirements for stretch-induced membrane traffic at the apical surface of bladder umbrella cells. Mol Biol Cell. 2009;20(1): 282-295.

38. Kreft ME, Romih R, Kreft M, Jezernik K. Endocytotic activity of bladder superficial urothelial cells is inversely related to their differentiation stage. Differentiation. 2009;77(1):48-59.

39. Cooper EH. The biology of bladder cancer. Ann R Coll Surg Engl. 1972;51(1):1-16.

40. Martin BF. Cell replacement and differentiation in transitional epithelium: a histological and autoradiographic study of the guinea-pig bladder and ureter. J Anat. 1972;112(Pt 3):433-455.

41. Erman A, Zupancic D, Jezernik K. Apoptosis and desquamation of urothelial cells in tissue remodeling during rat postnatal development. J Histochem Cytochem. 2009;57(8):721-730.

42. Veranic P, Erman A, Kerec-Kos M, Bogataj M, Mrhar A, Jezernik K. Rapid differentiation of superficial urothelial cells after chitosaninduced desquamation. Histochem Cell Biol. 2009;131(1):129-139.

43. Korosec P, Jezernik K. Early cellular and ultrastructural response of the mouse urinary bladder urothelium to ischemia. Virchows Arch. 2000;436(4):377-383.
44. Veranic P, Jezernik K. Succession of events in desquamation of superficial urothelial cells as a response to stress induced by prolonged constant illumination. Tissue Cell. 2001;33(3):280-285.

45. Arai M, Kani T, Sugihara S, et al. Scanning and transmission electron microscopy of changes in the urinary bladder in rats treated with N-butylN-(4-hydroxybutyl)nitrosoamine. Gann. 1974;65(6):529-540.

46. Ariel I, Ayesh S, Gofrit O, et al. Gene expression in the bladder carcinoma rat model. Mol Carcinog. 2004;41(2):69-76.

47. Hu P, Meyers S, Liang FX, et al. Role of membrane proteins in permeability barrier function: uroplakin ablation elevates urothelial permeability. Am J Physiol Renal Physiol. 2002;283(6):F1200-F1207.

48. Dreaden EC, Mackey MA, Huang X, Kang B, El-Sayed MA. Beating cancer in multiple ways using nanogold. Chem Soc Rev. 2011;40(7): 3391-3404.

49. Jain KK. Advances in the field of nanooncology. BMC Med. 2010;8:83

50. Jain S, Hirst DG, O’Sullivan JM. Gold nanoparticles as novel agents for cancer therapy. Br J Radiol. 2012;85(1010):101-113.

51. Thurn KT, Brown E, Wu A, et al. Nanoparticles for applications in cellular imaging. Nanoscale Res Lett. 2007;2(9):430-441.
International Journal of Nanomedicine

\section{Publish your work in this journal}

The International Journal of Nanomedicine is an international, peerreviewed journal focusing on the application of nanotechnology in diagnostics, therapeutics, and drug delivery systems throughout the biomedical field. This journal is indexed on PubMed Central,

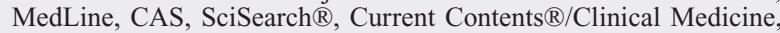

\section{Dovepress}

Journal Citation Reports/Science Edition, EMBase, Scopus and the Elsevier Bibliographic databases. The manuscript management system is completely online and includes a very quick and fair peer-review system, which is all easy to use. Visit http://www.dovepress.com/ testimonials.php to read real quotes from published authors. 